\title{
Radiographic characteristics of wrists in idiopathic carpal tunnel syndrome patients
}

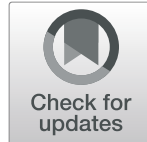

Kazuhiro Ikeda ${ }^{1}$, Yuichi Yoshii ${ }^{*}$, Takeshi Ogawa ${ }^{2}$ and Tomoo Ishii ${ }^{1}$

\begin{abstract}
Background: To determine the radiographic characteristics of wrists in idiopathic carpal tunnel syndrome patients, we compared the radiographic parameters of the wrists between carpal tunnel syndrome patients and nonsymptomatic controls.

Methods: We evaluated radiographic parameters of 94 wrists of 62 idiopathic carpal tunnel syndrome patients and 94 asymptomatic wrists of 94 controls. Carpal tunnel syndrome was diagnosed by clinical findings and nerve conduction studies. The lack of symptoms was confirmed with the medical records and interviews for the controls. X-ray images of the postero-anterior and lateral views of the wrist were taken. Using the obtained X-ray images, the indices of radial inclination, volar tilt, ulnar variance, and transverse and antero-posterior diameters of the wrists were measured. Two raters independently performed the measurement. One rater measured without information of clinical symptoms. Inter-rater reliabilities for each parameter were evaluated by the intra-class correlation coefficients. The averages of the measurements of two raters were compared between the carpal tunnel syndrome patients and the controls.

Results: The intra-class correlation coefficients were 0.58 for radial inclination, 0.77 for ulnar variance, 0.99 for transverse diameter, 0.60 for volar tilt, and 0.91 for antero-posterior diameter. Statistically significant correlations were found for all parameters $(P<0.01)$. The ulnar variance was significantly larger in the carpal tunnel syndrome patients compared to the controls $(1.7+/-1.8 \mathrm{~mm}$ and $0.8+/-1.5 \mathrm{~mm}$ for the patients and controls, respectively $P<0.01)$. There were no significant differences in the other parameters.
\end{abstract}

Conclusions: Significant differences in the ulnar variance were observed between carpal tunnel syndrome patients and controls. This suggests that the imbalance of radioulnar bone length is one of the risk factors to develop carpal tunnel syndrome. The positive ulnar variance may be an index that needs attention to the development of carpal tunnel syndrome.

Level of evidence: level III, a case control study.

Keywords: Carpal tunnel syndrome, X-ray, Ulnar variance, Volar tilt, Radial inclination

\footnotetext{
* Correspondence: yyoshii@tokyo-med.ac.jp

'Department of Orthopaedic Surgery, Tokyo Medical University Ibaraki

Medical Center, 3-20-1 Chuo, Ami, Inashiki, Ibaraki 300-0395, Japan

Full list of author information is available at the end of the article
}

C C The Author(s). 2020 Open Access This article is licensed under a Creative Commons Attribution 4.0 International License, which permits use, sharing, adaptation, distribution and reproduction in any medium or format, as long as you give appropriate credit to the original author(s) and the source, provide a link to the Creative Commons licence, and indicate if changes were made. The images or other third party material in this article are included in the article's Creative Commons licence, unless indicated otherwise in a credit line to the material. If material is not included in the article's Creative Commons licence and your intended use is not permitted by statutory regulation or exceeds the permitted use, you will need to obtain permission directly from the copyright holder. To view a copy of this licence, visit http://creativecommons.org/licenses/by/4.0/. The Creative Commons Public Domain Dedication waiver (http://creativecommons.org/publicdomain/zero/1.0/) applies to the data made available in this article, unless otherwise stated in a credit line to the data. 


\section{Background}

Carpal tunnel syndrome (CTS) is one of the most common peripheral neuropathies [1]. There are several etiologies of carpal tunnel syndrome including idiopathic, wrist trauma, oral contraceptives, pregnancy, arthritis, collagenvascular diseases, diabetes, hypothyroidism, and occupations or hobbies that involve repetitive motion of the wrist [2]. When considering the risk factors of median nerve compression in the carpal tunnel, it is necessary to consider the size of the carpal tunnel and the local factor narrowing the tunnel. It has been suggested that carpal tunnel narrowness is one of the risk factors, because idiopathic CTS develops at a high rate in women with a small carpal tunnel cross-sectional area [3]. Anatomically, there are two sites of median nerve compression, i.e., the proximal edge of the carpal tunnel and the narrowest portion at the hook of hamate. Because of the changes in thickness and rigidity between the proximal portion of the flexor retinaculum and the forearm facia, changes of fluid pressure in the carpal tunnel have been reported with wrist movement [4].

It is well known that CTS develops as a late stage disorder associated with deformity healing after distal radius fracture [5-9]. Several reports have analyzed the pathogenesis of CTS following distal radius fractures and discussed predisposing risk factors [6, 8, 10-15]. It has been suggested that an abnormal course of the median nerve at the wrist or carpal tunnel volume loss due to malunion of the distal radius is one of the pathomechanisms involved in the development of CTS [3]. This suggests that morphology of the wrist joints may also play an important role for the etiology of idiopathic CTS. To know the morphology of the wrists, simple X-ray are widely used. Simple wrist X-ray can provide morphological image of wrist more easily and quickly than other radiological examinations with low cost. In addition, morphometry in plain radiographs are useful to identify the characteristics of wrist joint. If wrist morphometric parameters are related to the pathology of CTS, it may be useful in predicting or estimating the risk of carpal tunnel syndrome. However, there were few reports that evaluated the morphology of the wrist in idiopathic CTS patients. The significance of radiography in carpal tunnel syndrome has not been established. To assess the radiographic characteristics in CTS patients, we compared the roentgenographic parameters of the wrists between CTS patients and non-symptomatic controls. We hypothesized that individuals with idiopathic CTS may have differences in the radiographic findings of their wrists compared with healthy individuals.

\section{Methods}

This was a case control study (level of evidence: level III). The study protocol was approved by our Institutional Review Board. Table 1 shows the average age and the number of male and female cases for both groups. CTS patients were diagnosed during the period from October 2011 to December 2017. The controls were randomly chosen from the list of persons who took wrist Xray during the same period and matched the age/gender to the CTS patients. Ninety-four wrists of 62 idiopathic CTS patients (male: 42 hands, female: 52 hands) and 94 asymptomatic wrists of 94 controls (male: 40 hands, female: 54 hands) were evaluated. There were 31 CTS patients (14 male, 17 female) who had both hands symptoms. There were no significant differences between CTS patients and controls for the age distribution and gender ratio.

CTS was diagnosed by clinical findings such as numbness and sensory disturbance on the radial side of the ring finger from the thumb finger, and having at least one positive provocative test result (Tinel's sign at the wrist and Phalen's maneuver). Thenar muscle atrophy was also considered one positive finding for the diagnosis of CTS. All patients underwent nerve conduction study and ultrasound imaging. The CTS diagnosis was confirmed with clinical symptoms and meeting the criteria of nerve conduction velocity findings with the American Association of Electrodiagnostic Medicine (AAEM) guidelines [16]. CTS patients with a history of systemic disease associated with a higher incidence of CTS, such as chronic renal failure, thyroid disease, diabetes, obesity (=body mass index greater than or equal to 30), or rheumatoid arthritis, were excluded. In addition, patients with a history of any upper extremity trauma were excluded. There were no anatomical variants in the wrists or space occupying lesions in the carpal tunnel in any of the CTS patients. X-ray of the postero-anterior and lateral view of the wrists were taken for both CTS patients and controls. The control wrists which had taken the wrist X-ray for a screening test or for comparison with the symptomatic wrist, excepting the symptoms of CTS, were obtained from our

Table 1 Average age and gender of both groups

\begin{tabular}{lllll}
\hline & Age & Male & Female & Total \\
\hline CTS Patients & $65.2 \pm 13.2$ & 28 (42 Hands) & 35 (52 Hands) & 62 (94 Hands) \\
Control & $64.1 \pm 13.9$ & 40 (40 Hands) & 54 (54 Hands) & 94 (94 Hands) \\
$P$ value & 0.64 & 0.88 & & $/$ \\
\hline
\end{tabular}

The patients and controls were age/gender matched 
medical records. The lack of symptoms were confirmed with the medical records and interviews for the controls. The controls were age and gender matched with the CTS patients. The X-rays were taken at the initial consultation for their symptoms in both groups.

The radiology technicians who took the X-ray images were blinded to the clinical symptoms. The posteroanterior view was obtained with the elbow flexed 90 degrees (the ulna perpendicular to the humerus) and the forearm in the pronated position. The lateral view was obtained with the elbow flexed 90 degrees and adducted against the trunk. The wrists were in a neutral position with no flexion, extension, or deviation in either view. Using the obtained X-ray images, the indices of radial tilt, volar tilt, ulnar variance, and transverse and antero-posterior diameters of the wrists were measured with image analyzing software (Synapse Vincent, Fujifilm Holdings Co., Fig. 1). The radial inclination, ulnar variance, volar tilt are most often used parameters to identify malalignment of the wrist [17]. The transverse and antero-posterior diameter were measured to estimate the carpal tunnel sizes. The angle between a line from the dorsal edge to the volar edge of the radius and the line perpendicular to the longitudinal axis of the radius was measured as the volar tilt. The angle between a line from the radial styloid tip to the ulnar aspect of the distal radius and a line perpendicular to the longitudinal axis of the radius was measured as the radial inclination. The transverse diameter was defined as the distance between the radial edge of the radius and the ulnar edge of the ulna at the level of the radio-carpal joint. The anteroposterior diameter was defined as the distance between the volar and dorsal edge of the distal radius. Two raters (A, B) independently performed the measurement. The rater $\mathrm{B}$ measured without information of clinical symptoms.

\section{Statistical analysis}

The results are expressed as mean $+/$ - standard deviation. Inter rater reliabilities for each parameter were evaluated by the intraclass correlation coefficients (ICC) for the raters $\mathrm{A}$ and $\mathrm{B}$ measurements. The parameters were compared between the CTS patients and the controls. For the normality test of datasets, the ShapiroWilk test was used. Welch's t-test was applied in normal distribution indices (volar tilt, antero-posterior diameter) and Mann-Whitney's U test was applied in non-normal distribution indices (radial inclination, ulnar variance, and transverse diameter). The averages of the measurements of the two raters were compared between the

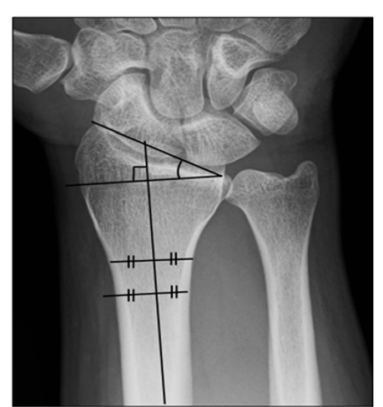

(a)

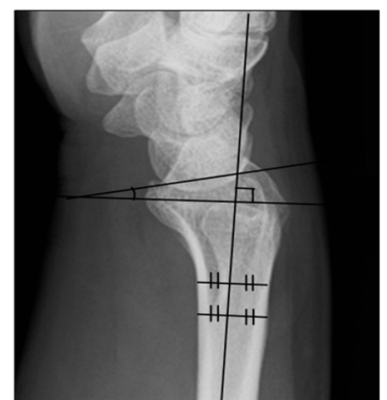

(d)

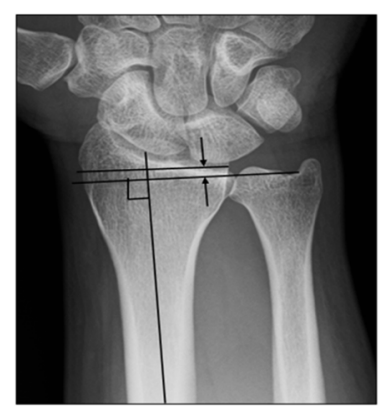

(b)

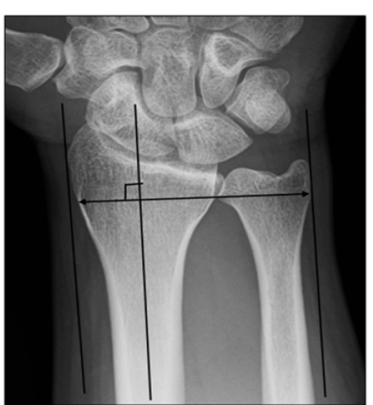

(c)

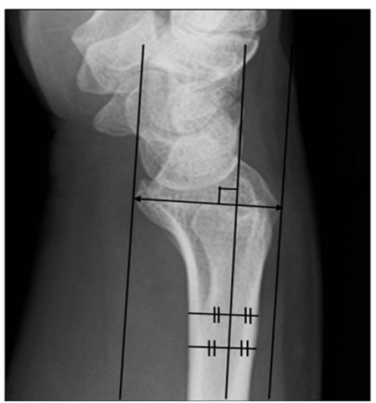

(e)

Fig. 1 Measurements of roentgenographic indices. a Radial inclination was defined as the angle between one line connecting the radial styloid tip and the ulnar aspect of the distal radius and a second line perpendicular to the longitudinal axis of the radius. $\mathbf{b}$ Ulnar variance was defined as the relative lengths of the distal articular surfaces of the radius (middle line of the surface) and ulna (fovea). c The transverse diameter was defined as the distance between the radial edge of the radius and the ulnar edge of the ulna at the level of the radio-carpal joint. $\mathbf{d}$ Volar tilt was defined as the angle of the distal radial surface with respect to a line perpendicular shaft. e The antero-posterior diameter was defined as the distance between the volar and dorsal edge of the distal radius 
CTS patients and the controls. $P$ values of $<0.05$ were considered significant. The diagnostic potentials of the parameters were assessed by the receiver operating characteristic (ROC) curves. Performances of the diagnostic variables were quantified by calculating the area under the ROC curve (AUC) for the parameters. The cut-off values on the ROC curves were defined by the highest point on the vertical axis and the point furthest to the left on the horizontal axis (upper left corner). All analyses were performed using BellCurve for Excel version 2.12 (SSRI Co., Tokyo, Japan).

\section{Results}

The results of correlations between rater A and B are shown in Fig. 2. Statistically significant correlations were found for all parameters $(P<0.01)$. The intra-class correlation coefficients were 0.58 for radial inclination, 0.77 for ulnar variance, 0.99 for transverse diameter, 0.60 for volar tilt, and 0.91 for antero-posterior diameter. The transverse diameter showed the highest correlations. The radial inclination showed the lowest correlations.
The results of the roentgenographic indices for the CTS patients and controls are shown in Fig. 3. The radial inclinations were $26.6+/-2.2$ degrees and $26.4+/-$ 2.8 degrees for the CTS patients and controls, respectively $(P=0.71)$. The ulnar variances were $1.7+/-1.8 \mathrm{~mm}$ and $0.8+/-1.5 \mathrm{~mm}$ for the CTS patients and controls, respectively $(P<0.01)$. The transverse diameters were $49.6+/-4.2 \mathrm{~mm}$ and $49.7+/-4.2 \mathrm{~mm}$ for the CTS patients and controls, respectively $(P=0.80)$. The volar tilts were15.2 $+/-3.8$ degrees and $59.8+/-6.4$ degrees, respectively $(P=0.67)$. The antero-posterior diameters were $25.4+/-2.7 \mathrm{~mm}$ and $25.9+/-2.5 \mathrm{~mm}$ for the CTS patients and controls, respectively $(P=0.20)$. The ulnar variances were significantly larger in the CTS patients compared to the controls.

The results of ROC curve analysis are shown in Fig. 4. The cut-off values and odds ratios for each parameter are shown in Table 2. The AUC values were 0.52, 0.65, $0.51,0.52$ and 0.55 for the radial inclination, ulnar variance, transverse diameter, volar tilt, and antero-posterior diamter, respectively. The ulnar variance had the highest

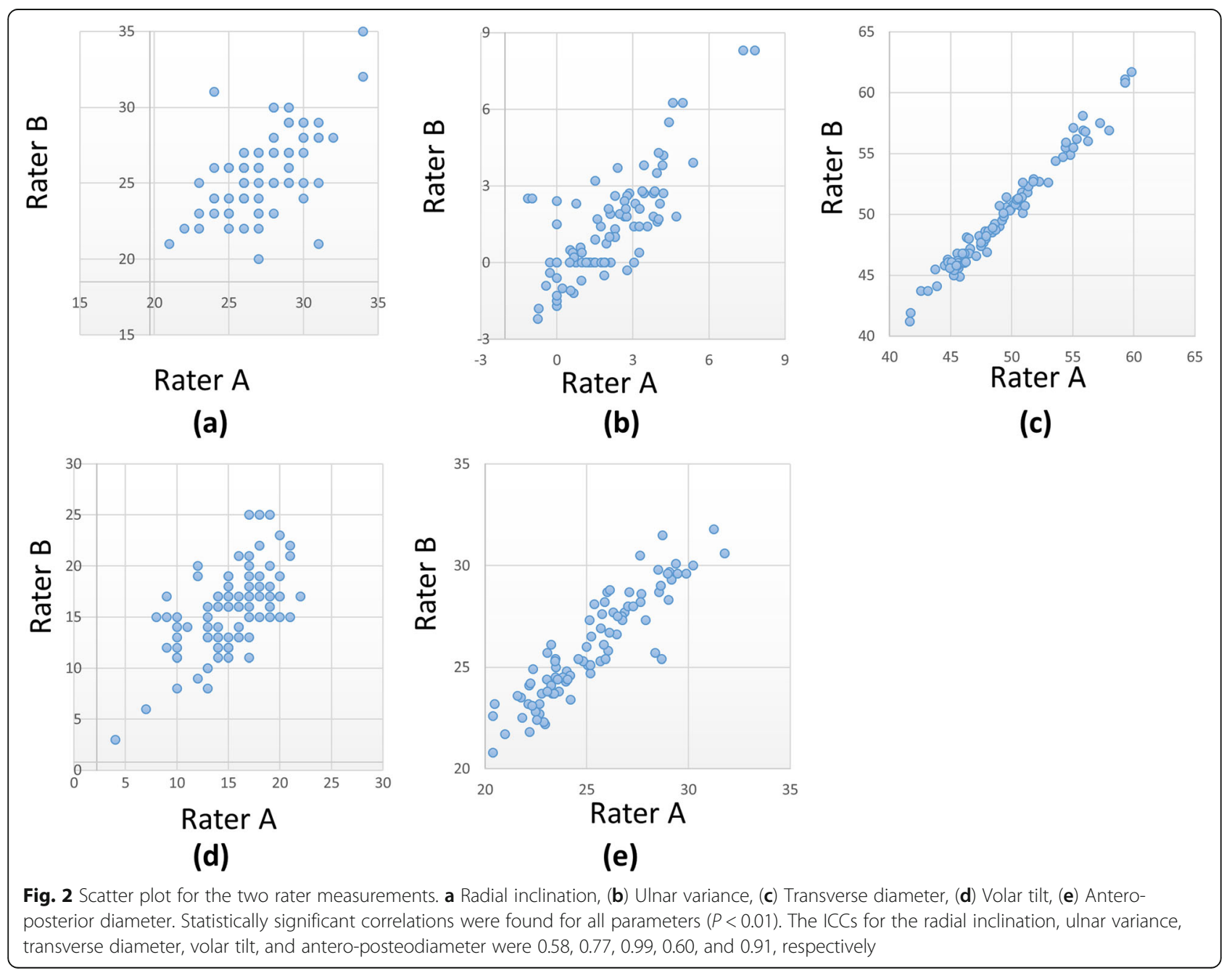




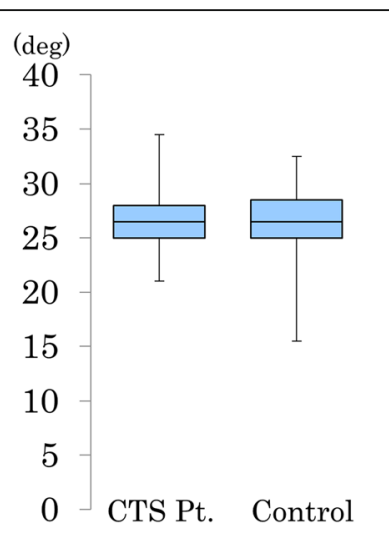

(a)

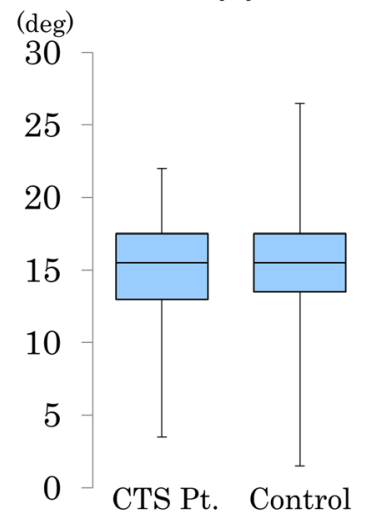

(d)

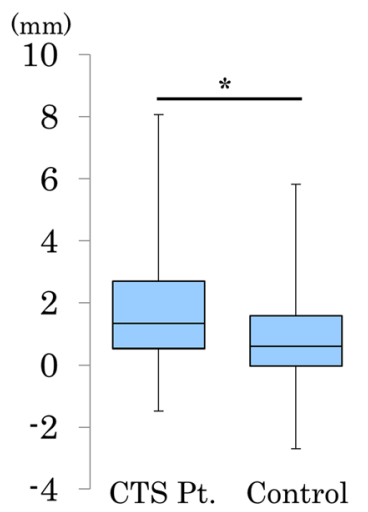

(b)

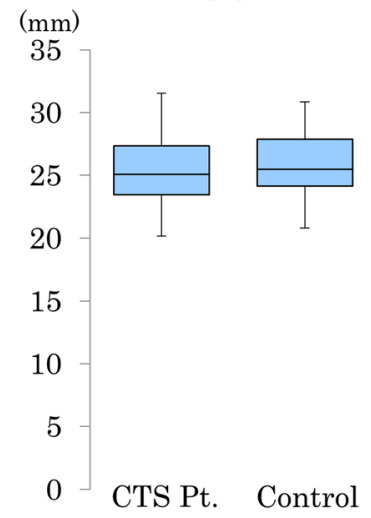

(e)

Fig. 3 Results of roentgenographic indices. a Radial inclination, (b) Ulnar variance, (c) Transverse diameter, (d) Volar tilt, (e) Antero-posterior diameter. The ulnar variance was significantly larger in the CTS patients compared with the controls (*: P < 0.01)

AUC value, and the transverse diameter had the lowest. The cut-off value to discriminate individuals at risk of CTS from the asymptomatic control was $0.58 \mathrm{~mm}$.

\section{Discussion}

Several factors are involved in the onset of idiopathic CTS. Mechanical stress to subsynovial connective tissue accompanying flexion-extension of the wrist or fingers is considered to be a leading factor for the development of CTS [18]. Natural carpal tunnel narrowness is presumed to be another risk factor [3]. The other reports showed no significant differences in the carpal tunnel crosssectional area between idiopathic CTS patients and healthy controls $[19,20]$. It is well known that CTS develops as a late stage disorder associated with malunions of distal radius fractures $[8,10,13,21]$. This suggests that the morphology of wrist joints (radiocarpal, ulnocarpal and distal radioulnar joints) may affect the development of CTS.

The usefulness of plain radiography for the diagnosis of CTS was uncorroborated. The advantages of taking $\mathrm{X}$-ray are simple, quick, possibility of multiple inspections, and low cost. The disadvantages of the X-ray is that it is unable to see the soft tissues. As it cannot reveal the abnormalities in the soft tissues that constitute carpal tunnel, plain radiography had been considered to have a limited role for the diagnosis of idiopathic CTS [22-24]. It could be useful only in cases associated with bony stenosis, fracture and soft tissue calcification. There was a report showing only $0.4 \%$ of cases with specific findings in plain radiograph related to treatment policy [24]. Therefore, it was suggested that plain radiograph should not be taken as a routine CTS diagnostic tool unless hard tissue-related changes were suspected. Recent advances in imaging techniques in ultrasound and MRI, i.e., shear wave elastography [25], pressuremonitor elastography [26], diffusion tensor imaging of MRI [27], have been reported to be more beneficial in diagnosing neurological conditions of carpal tunnel syndrome.

To date, there are few studies which showing the significance of X-ray measurements for the assessment of CTS. The reasons for measuring the indices of radial inclination, volar tilt, ulnar variance, and transverse and antero-posterior diameters, are their widespread use and simplicity/reproducibility of measurements. If the size of 


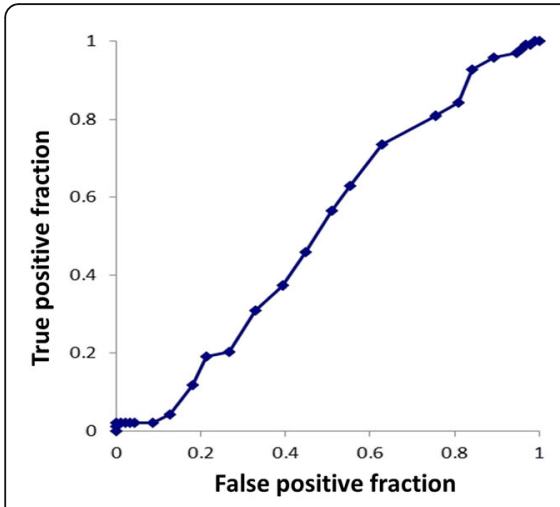

(a)

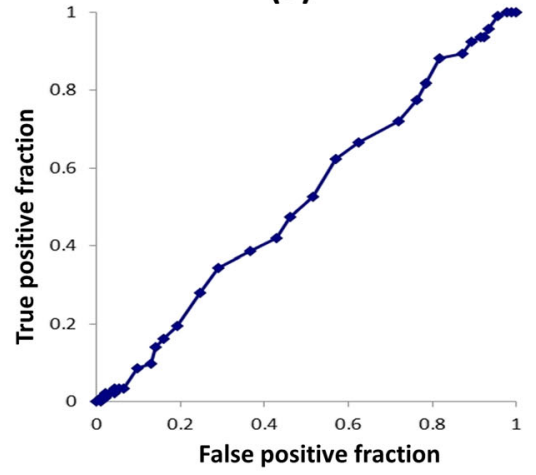

(d)

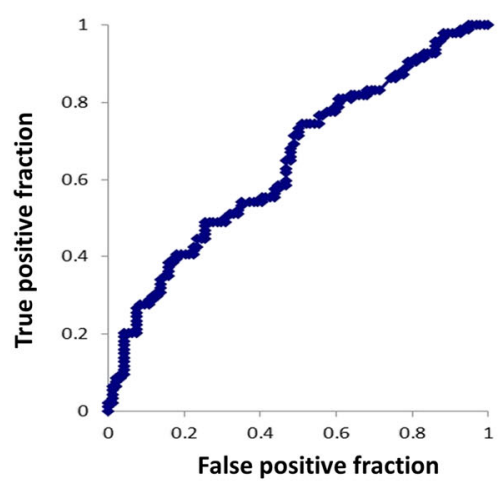

(b)

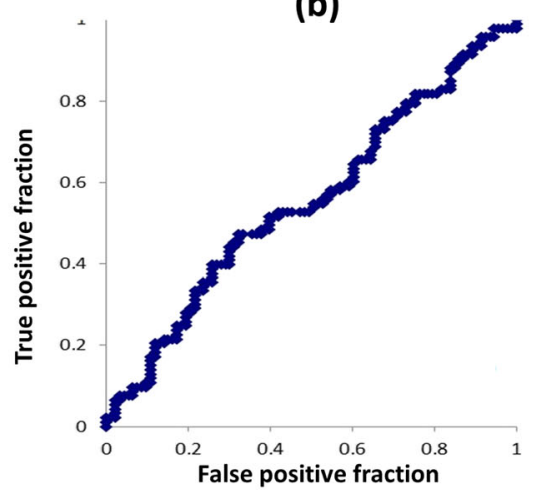

(e)

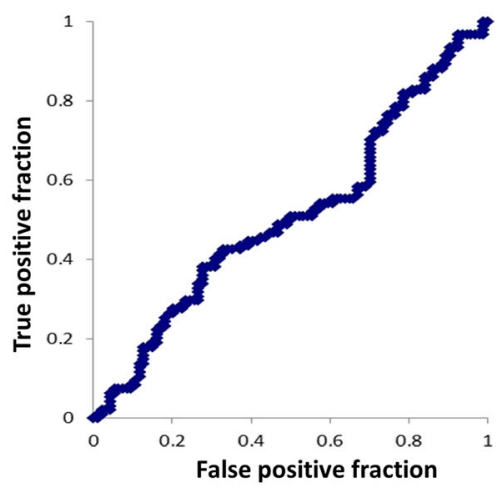

(c)

Fig. 4 Results of ROC curve analysis. a Radial inclination, (b) Ulnar variance, (c) Transverse diameter, (d) Volar tilt, (e) Antero-posterior diameter

the wrist joint is small, it is expected that the carpal tunnel would be small. However, the wrist size parameters of antero-posterior diameter/ transverse diameter did not differ between the groups. On the other hand, there was a significant difference in the ulnar variance between CTS patients and controls. This suggests that carpal tunnel syndrome was not due to native bony carpal tunnel narrowness, but rather due to imbalance of distal radio-ulnar joint. The uniqueness of this study was that it could reveal the difference between CTS patients and controls in one morphological parameter of the wrist. The positive ulnar variance may be recognized as one of the risk factors of developing CTS with larger studies. In a study of CTS with distal radius malunions, the residual dorsal angle of

Table 2 Results of ROC curve analysis

\begin{tabular}{llll}
\hline & AUC values & Cut-off values & Odds Ratio \\
\hline Radial inclination & 0.52 & $26 \mathrm{deg}$ & 1.4 \\
Ulnar variance & 0.65 & $0.58 \mathrm{~mm}$ & 2.8 \\
Transverse diameter & 0.51 & $47.9 \mathrm{~mm}$ & 1.5 \\
Volar tilt & 0.52 & $16 \mathrm{deg}$ & 1.3 \\
Antero-posterior diameter & 0.55 & $24.7 \mathrm{~mm}$ & 1.9 \\
\hline
\end{tabular}

The cut-off values on the ROC curves were defined by the highest point on the vertical axis and the point furthest to the left on the horizontal axis (upper left corner) the distal radius had a statistically significant correlation with the occurrence of CTS [15]. The carpal tunnel is narrowed with volar flexion of the midcarpal joint, dorsiflexion of the lunate, shortening and dorsal tilt of the radius $[10,22]$. More than $60 \%$ of wrists in CTS after distal radius fracture had unacceptable deformity of the distal radius [7]. Due to the distal radius malunion, the median nerve is placed in a narrow carpal tunnel and abnormal pathway. This suggests that the anatomical configuration of the proximal carpal tunnel due to the distal radius shape may be one of the main causes of CTS. Therefore, we expected that the volar tilt and radial inclination would be different when comparing between CTS patients and controls. However, there were no significant differences in these parameters. This suggests that the volar tilt and radial inclination in normal range would not be a risk of development of CTS.

The biomechanical conditions of positive ulnar variances is similar to the wrist changes in the CTS after distal radius fracture. It has been thought that shortening of the radius lead to narrowness of the carpal tunnel $[9,28]$. Normally, $80 \%$ of load applied to the wrist were transmitted through radius, and $20 \%$ were transmitted through ulna. The positive ulnar variance will increase the load bearing by the ulnocarpal joint [29]. In addition, there was a report which showed a positive relationship 
between decreased cross-sectional area around the distal radioulnar joint and positive ulnar variance on radiologic investigation [30]. Although there is no direct relationship between positive ulnar variance and median nerve compression, the positive ulnar variance may affect the development of CTS through the load on the ulnocarpal joint.

There were several limitations in this study. First, the definition of normal controls needs further consideration. We selected X-rays of asymptomatic wrists showing no symptoms at the time of the hospital visit. It is uncertain as to whether the control subjects will develop CTS in the future. We enrolled control subjects from among individuals visiting the hospital, who may not be representative of the general population. Second, there is only one X-ray taken per patient. To assess the reproducibility of each measurement, it may have been necessary to evaluate at multiple time points. Finally, since each measurement value for both groups was within the normal range, the parameters showing significant differences between CTS and controls are useful as a relative index.

\section{Conclusions}

The knowledge of a particular, quantifiable, predisposing factor for CTS would be of great interest for prevention and early diagnosis. Our results suggest that the imbalance of radioulnar bone length is one of the risk factors to develop carpal tunnel syndrome. The positive ulnar variance may be an index that needs attention to the development of carpal tunnel syndrome.

\section{Abbreviations}

CTS: Carpal tunnel syndrome; AAEM: American association of electrodiagnostic medicine; ICC: Intraclass correlation coefficients; ROC: Receiver operating characteristic; AUC: Area under the ROC curve

\section{Acknowledgements}

Not applicable.

\section{Authors' contributions}

Kl: analysis of the data, write manuscript, YY: research design, analysis of the data, write manuscript, TO: objective evaluation of data, write manuscript, TI: research design, write manuscript. All authors were fully involved in the study and approved final version of this manuscript.

\section{Funding}

Not applicable.

\section{Availability of data and materials}

The datasets analyzed during the current study are available from the corresponding author on reasonable request.

\section{Ethics approval and consent to participate}

The protocol for this study was reviewed and approved by our Institutional Review Board of Tokyo Medical University Ibaraki Medical Center (No.14-5). This was a retrospective study. The IRB waived the requirement to obtain a signed consent form.

\section{Consent for publication}

Not applicable.

\section{Competing interests}

None of the authors has any conflict of interest to disclose.

\section{Author details}

'Department of Orthopaedic Surgery, Tokyo Medical University Ibaraki Medical Center, 3-20-1 Chuo, Ami, Inashiki, Ibaraki 300-0395, Japan.

${ }^{2}$ Department of Orthopaedic Surgery, Mito Kyodo General Hospital, Tsukuba University Hospital Mito Area Medical Education Center, Mito 310-0015, Japan.

Received: 12 September 2019 Accepted: 31 March 2020

Published online: 15 April 2020

\section{References}

1. Aroori S, Spence RA. Carpal tunnel syndrome. Ulster Med J. 2008;77:6-17 https://www.ncbi.nlm.nih.gov/pmc/articles/PMC2397020/.

2. MacDermid JC, Doherty T. Clinical and electrodiagnostic testing of carpal tunnel syndrome: a narrative review. J Orthop Sports Phys Ther 2004;34: 565-588. https:/www.jospt.org/doi/abs/https://doi.org/10.2519/jospt.2004. 34.10.565.

3. Dekel S, Papaioannou T, Rushworth G, Coates R. Idiopathic carpal tunnel syndrome caused by carpal tunnel stenosis. Br Med J. 1980;280:1297-9 https://www.ncbi.nlm.nih.gov/pmc/articles/PMC1601593/.

4. Werner RA, Andary M. Carpal tunnel syndrome: pathophysiology and clinical neurophysiology. Clin Neurophysiol. 2002;113:1373-81 https://www. sciencedirect.com/science/article/pii/S1388245702001694.

5. Altissimi M, Antenucci R, Fiacca C, Mancini GB. Long-term results of conservative treatment of fractures of the distal radius. Clin Orthop Relat Res. 1986;206:202-10 https://www.ncbi.nlm.nih.gov/pubmed/3708976.

6. Cooney WP, Dobyns JH, Linscheid RL. Complications of Colles' fractures. J Bone Joint Surg Am. 1980;62:613-9 https://insights.ovid.com/ pubmed?pmid $=6155380$.

7. Frykman G. Fractures of the distal radius including sequelae-shoulder-handfinger syndrome, disturbance in the distal radio-ulnar joint and impairment of nerve function. Acta Orthop Scand. 1967;Suppl 108:1-153 https://www. ncbi.nlm.nih.gov/pubmed/4175195.

8. Lynch AC, Lipscomb PR. The carpal tunnel syndrome and Colles' fractures. JAMA. 1963;185:363-6 https://jamanetwork.com/journals/jama/ fullarticle/666436.

9. Pool C. Colles' fracture. A prospective study of treatment. J Bone Joint Surg Br. 1973:55:540-4 https://www.ncbi.nlm.nih.gov/pubmed/4125714.

10. Aro H, Koivunen T, Katevuo K, Niemien S, Aho AJ. Late compres- Sion neuropathies after Colles' fractures. Clin Orthop Relat Res. 1988;233:217-25 https://www.ncbi.nlm.nih.gov/pubmed/3402127.

11. Fernandez DL, Palmer AK. Fractures of the distal radius. In: Green DP, Hotchikiss RN, Pederson WC,editors. Green's operative hand surgery. Pennsylvania: Churchill Livingstone 1999;929-985.

12. Kongsholm J, Olerud C. Carpal tunnel pressure in the acute phase after Colles' fracture. Arch Orthop Trauma Surg. 1986;105:183-6 https://www.ncbi. nlm.nih.gov/pubmed/3741071.

13. Lewis MH. Median nerve decompression after Colles's fracture. J Bone Joint Surg Br 1978;60-B:195-196. https://online.boneandjoint.org.uk/doi/abs/ https://doi.org/10.1302/0301-620X.60B2.659462.

14. Sponsel KH, Palm ET. Carpal tunnel syndrome following Colles' fracture. Surg Gynecol Obstet. 1965;121:1252-6 https://www.ncbi.nlm.nih.gov/ pubmed/5851620.

15. Stewart HD, Innes AR, Burke FD. The hand complications of Colles' fractures. J Hand Surg Br. 1985;10:103-6 https:/www.ncbi.nlm.nih.gov/pubmed/3998585.

16. Jablecki CK, Andary MT, Floeter MK, Miller RG, Quartly CA, Vennix MJ, Wilson JR. Practice parameter: electrodiagnostic studies in carpal tunnel syndrome. Report of the American Association of Electrodiagnostic Medicine, American Academy of Neurology, and the American Academy of physical medicine and rehabilitation. Neurology. 2002;58:1589-92 https:/www.ncbi.nlm.nih. gov/pubmed/12058083.

17. Lalone EA, Grewal R, King GJ, MacDermid JC. A structured review addressing the use of radiographic measures of alignment and the definition of acceptability in patients with distal radius fractures. Hand (N Y). 2015;10:621-38 https://www.ncbi.nlm.nih.gov/pmc/articles/PMC4641087.

18. Ettema AM, Amadio PC, Zhao C, Wold LE, An KN. A histological and immunohistochemical study of the subsynovial connective tissue in 
idiopathic carpal tunnel syndrome. J Bone Joint Surg Am. 2004;86-A:1458-66 https:/www.ncbi.nlm.nih.gov/pubmed/15252093,

19. Merhar GL, Clark RA, Schneider HJ, Stern PJ. High- resolution computed tomography of the wrist in the patients with carpal tunnel syndrome. Skelet Radiol. 1986;15:549-52 https://www.ncbi.nlm.nih.gov/pubmed/3775421.

20. Pierre-Jerome C, Bekkelund SI, Mellgren SI, Nordstrøm R. Quantitative MRI and electrophysiology of preoperative carpal tunnel syndrome in a female population. Ergonomics. 1997;40:642-9 https://www.ncbi.nlm.nih.gov/ pubmed/9174415.

21. Watanabe K, Ota H. Carpal malalignment as a predictor of delayed carpal tunnel syndrome after Colles' fracture. Plast Reconstr Surg Glob Open. 2019; 7:e2165 https://www.ncbi.nlm.nih.gov/pubmed/31044126.

22. Buchberger W. Radiologic imaging of the carpal tunnel. Eur J Radiol. 1997; 25:112-7 https://www.sciencedirect.com/science/article/pii/S072004 8X97000387.

23. Ghasemi-Rad M, Nosair E, Vegh A, Mohammadi A, Akkad A, Lesha E, Mohammadi MH, Sayed D, Davarian A, Maleki-Miyandoab T, Hasan A. A handy review of carpal tunnel syndrome: from anatomy to diagnosis and treatment. World J Radiol. 2014;6:284-300 https://www.wjgnet.com/1949-84 70/full/v6/i6/284.htm.

24. Bindra RR, Evanoff BA, Chough LY, Cole RJ, Chow JC, Gelberman RH. The use of routine wrist radiography in the evaluation of patients with carpal tunnel syndrome. J Hand Surg Am. 1997;22:115-9 https://www.ncbi.nlm.nih. gov/pubmed/9018623.

25. Zhang C, Li M, Jiang J, Zhou Q, Xian G L, Huang Y, Ban W, Peng W. Diagnostic value of virtual touch tissue imaging quantification for evaluating median nerve stiffness in carpal tunnel syndrome. J Ultrasound Med 2017;36:1783-1791. https://onlinelibrary.wiley.com/doi/full/https://doi. org/10.1002/jum.14213.

26. Yoshii Y, Tung $\mathrm{WL}$, Yuine $H$, Ishii T. Postoperative diagnostic potentials of median nerve strain and applied pressure measurement after carpal tunnel release. BMC Musculoskelet Disord. 2020;21:22 https://www.ncbi.nlm.nih. gov/pmc/articles/PMC6955092.

27. Wang $H$, Ma J, Zhao L, Wang $Y$, Jia X. Utility of MRI diffusion tensor imaging in carpal tunnel syndrome: a meta-analysis. Med Sci Monit. 2016;22:736-42 https://www.ncbi.nlm.nih.gov/pmc/articles/PMC4784544.

28. Crosby EB, Linscheid RL, Dobyns JH. Scaphotrapezial trapezoidal arthrosis. J Hand Surg Am. 1978;3:223-34 https:/www.ncbi.n/m.nih.gov/pubmed/659818.

29. Palmer AK. The distal radioulnar joint. Anatomy, biomechanics, and triangular fibrocartilage complex abnormalities. Hand Clin. 1987;3:31-40 https://www.ncbi.nlm.nih.gov/pubmed/3818811.

30. Cha SM, Shin HD, Song SH. Cross-sectional area just proximal to the carpa tunnel according to the ulnar variances: positive ulnar variance and carpal tunnel syndrome. Ann Plast Surg. 2019;82:76-81 https:/www.ncbi.nlm.nih. gov/pubmed/30300223.

\section{Publisher's Note}

Springer Nature remains neutral with regard to jurisdictional claims in published maps and institutional affiliations.

Ready to submit your research? Choose BMC and benefit from:

- fast, convenient online submission

- thorough peer review by experienced researchers in your field

- rapid publication on acceptance

- support for research data, including large and complex data types

- gold Open Access which fosters wider collaboration and increased citations

- maximum visibility for your research: over $100 \mathrm{M}$ website views per year

At $\mathrm{BMC}$, research is always in progress.

Learn more biomedcentral.com/submissions 